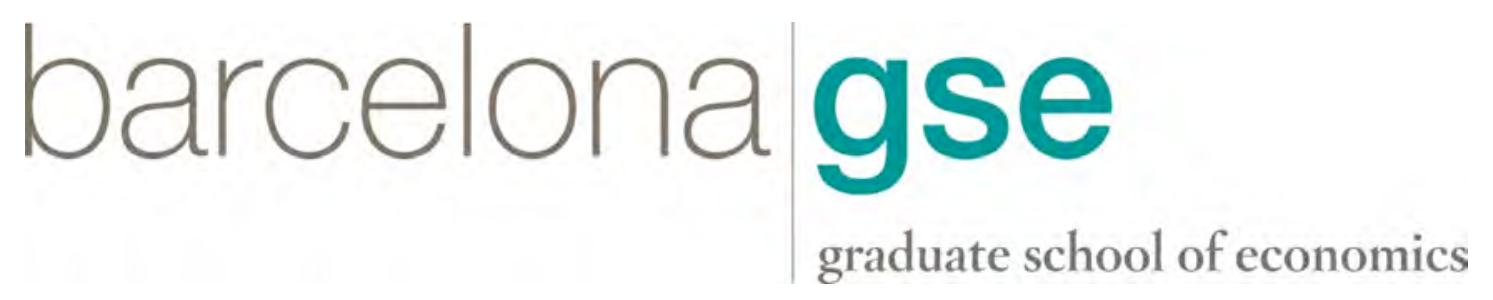

\title{
Monitoring Bank Performance in the Presence of Risk
}

\author{
Mircea Epure \\ Esteban Lafuente
}

This version: March 2014

(March 2012)

Barcelona GSE Working Paper Series

Working Paper $n^{\circ} 613$ 


\title{
Monitoring Bank Performance in the Presence of Risk
}

\author{
Mircea Epure $^{\dagger}$ \\ Department of Economics and Business \\ Universitat Pompeu Fabra and Barcelona GSE \\ Ramon Trias Fargas, 25-27, E-08005 Barcelona, Spain \\ Phone: +34 93542 2546, Fax: +34 935421746 \\ mircea.epure@upf.edu \\ Esteban Lafuente \\ Department of Management \\ Universitat Politècnica de Catalunya (Barcelona Tech) \\ EPSEB, Av. Gregorio Marañón, 44-50, E-08028 Barcelona, Spain \\ Phone: +34 93405 4476, Fax: +34 933348960 \\ esteban.lafuente@upc.edu
}

March 2012. This version: March 2014

\begin{abstract}
This paper proposes a managerial control tool that integrates risk in efficiency scores. Building on existing efficiency specifications, our proposal reflects the real banking technology and accurately models the relationship between desirable and undesirable outputs. Specifically, the undesirable output is defined as non-performing loans to capture credit risk, and is linked only to the relevant dimension of the output set. We empirically illustrate how our efficiency measure functions for managerial control purposes. The application considers a unique dataset of Costa Rican banks during 1998-2012. Efficiency scores' implications are mostly discussed at bank-level, and their interpretations are enhanced by using accounting ratios. We also show the usefulness of our tool for corporate governance by examining performance changes around executive turnover. Results confirm that appointing CEOs from outside the bank significantly improves performance, thus suggesting the potential benefits of new organisational practices.
\end{abstract}

Keywords: efficiency; risk; accounting; CEO turnover; banking; non-performing loans

JEL classification: G21; G28; G3; M1; M2

\footnotetext{
${ }^{\dagger}$ Corresponding author. We thank conference participants at the 2012 Asia-Pacific Productivity Conference in Bangkok and the XX Finance Forum in Oviedo for most constructive comments that substantially improved the paper. This research received financial support from the Spanish Ministry of Science and Innovation. Mircea Epure benefited from grant ECO2010-18967; Esteban Lafuente benefited from grant ECO2010-21393-C04-01. Usual disclaimers apply.
} 


\section{Introduction}

In this paper we propose a managerial control tool that integrates risk in efficiency estimations. Our new measure extends the work of Kuosmanen (2005) and is applied to the banking activity. Specifically, we devise an efficiency measure that reflects the real banking technology by accurately modelling the relationship between desirable and undesirable outputs, the latter of which represent credit risk. Our estimators match rationales of control (or monitoring) systems that are usually employed in banking. This study is thus embedded in the literature that assessed the relation between risk and bank efficiency and, on occasions, attempted to introduce risk in efficiency measures (see, e.g., Hughes and Mester (1998), Altunbas et al. (2000), Park and Weber (2006), Banker et al. (2010), Hsiao et al. (2010) or Barros et al. (2012)). Despite the various efforts, there remains a need to more directly use risk factors as an integrating part of efficiency analyses. Our new measure addresses this call for rigorous efficiency assessments that can be employed for managerial accounting control objectives. We illustrate our proposal via an empirical application that interprets efficiency in the presence of risk. Furthermore, we show how our monitoring tool can be employed for corporate governance purposes by examining executive turnover effects on future performance.

Bank efficiency has been analysed from multiple angles (see, e.g., the reviews of Berger and Humphrey (1997), Goddard et al. (2001) or Fethi and Pasiouras (2010)). Among these, a largely preferred approach relies on non-parametric efficiency frontier techniques. These methods, best known as Data Envelopment Analysis (DEA) are more suitable when multiple inputs are employed to obtain multiple outputs (see, e.g., Ray (2004)). Even if parametric models allow for stochastic errors, they have strong assumptions on functional distributions (which are not needed in non-parametric contexts) and do not allow for multiple objectives to be pursued or desirable and undesirable outputs to be jointly produced. The flexible nature of DEA is especially appealing for applications based on diverse management and accounting frameworks (Grifell-Tatjé and Lovell 1999; Banker et al. 2005). Hence, the literature on non-parametric efficiency analysis has experienced important developments (Cook and Seiford 2009; Cooper et al. 2011).

Although bank efficiency has been extensively scrutinised, few studies introduced explicit risk variables in efficiency measures. Initially, parametric analyses did so under cost function approaches (McAllister and McManus 1993; Berger and DeYoung 1997; Hughes and Mester 1998; Altunbas et al. 2000). For instance, Hughes and Mester (1998) used the level of financial capital as a risk signal that bank managers employ for controlling output quality. Altunbas et al. (2000) express quality of loans through the ratio of non-performing loans (NPL) to total loans. According to Berger and DeYoung (1997) and Van Hoose (2010) this variable captures the quality of monitoring over loans. There also exists a stream of literature that introduces risk in non-parametric bank efficiency analysis (Park and Weber 2006; Fukuyama and Weber 2010; Barros et al. 2012). In this case, risk takes the form of undesirable outputs, which for financial institutions are typically proxied through 
NPL. This variable illustrates credit risk, which is crucial for the long-run bank activity (Basel Committee of Banking Supervision 2011).

Yet, this latter stream of literature leaves two unaddressed issues. First, in typical production settings, desirable and undesirable outputs are jointly produced, in the sense that generating desirable outputs is not possible without generating undesirable outputs. This may not apply to banking activity, in which only certain outputs are linked to undesirable outputs such as NPL. Second, existing nonparametric banking studies that introduce credit risk in efficiency assessments often assume constant returns to scale, whereas the technology is more likely to exhibit variable returns to scale (VRS) (Chambers and Pope 1996).

To address these issues, the main contribution of this paper is to propose a tool for monitoring bank efficiency that integrates credit risk in efficiency analyses, while accurately defining the multiple-output bank technology. Due to these characteristics, our proposal is suitable for managerial control systems that aim at setting objectives and evaluating their degree of achievement. We start from the specification of Kuosmanen (2005) that properly models desirable and undesirable outputs when assuming VRS. We extend this model to correctly define the real banking technology. Specifically, undesirable outputs (NPL) are strictly linked only to that dimension of the output set that refers to credit (i.e. performing loans). The rest of outputs, such as investment portfolio or service fees, do not have a link with NPL.

We empirically illustrate how our monitoring tool functions for assessing bank performance. The efficiency assessment is systematically interpreted and compared with conventional accounting ratios (i.e. return on assets (ROA) and net interest margin (NIM)). Given the managerial control focus, implications are usually discussed at bank-level, whereas we also briefly consider some industry-level effects of risk on performance. We then employ our proposal to examine performance changes around executive turnover, a specific corporate governance mechanism. Corporate governance literature states that accurate monitoring ex ante signals managers' performance, while ex post monitoring is used to reveal potential gains from executive turnover (Hermalin and Weisbach 2003; Zhang and Rajagopalan 2010). This monitoring activity may well be done via our proposed measure.

The empirical application considers a unique dataset of Costa Rican banks between 1998 and 2012. This setting is attractive since it previously underwent important changes in the regulatory framework jointly with enhancements in monitoring practices. By 1997 bank activity was deregulated among the different players and the supervisory institution had all its monitoring functions in place. Thus, apart from the generally available accounting variables, the dataset presents well-structured information on NPL and organisational architecture. Moreover, in the first half of the analysed time span the monitoring over financial institutions was enhanced, and during the second half of the studied period the impact of the recent financial crisis can be observed (IMF 2003; 2013).

The remainder of this paper is structured as follows. Section 2 provides a brief overview of the existing literature on bank performance and risk, and the consequences of executive turnover on 
performance. Section 3 proposes our multidimensional efficiency measure in accordance with the theoretical underpinning presented. The Costa Rican banking industry is described in Section 4. In Section 5 the sample, variables and analysis stages are presented. Empirical results are found in Section 6, while the final section includes some concluding remarks.

\section{Theoretical underpinnings and the usefulness of efficiency monitoring tools}

Technology advances and different episodes of economic fluctuations that have occurred over the past decades led many administrations from developing and developed economies to restructure financial sectors. These legal reforms were introduced to strengthen and stabilise the now deregulated financial systems, and focused on the structure of banking industries and the accurate functioning of supervisory institutions (Yildirim and Philippatos 2007; Banker et al. 2010).

Following these profound reforms banks were expected to consolidate and improve their performance as legal changes aimed at enhancing, among others, risk management practices. Banks thus exert a more diligent oversight of their operations to signal their performance and safety to the market and supervisory agencies. The quality of risk management activities in banks is usually linked to credit risk and the levels of capital available to absorb potential financial losses. In this sense, monitoring activities are especially relevant when they are related to NPL's management. In consonance with Berger and DeYoung (1997), Altunbas et al. (2000) and Van Hoose (2010), this variable is considered endogenous, and can be modelled as a function of management effort.

As a result, bank outcomes can be seen as an informative signal about the manager's unobserved ability. Using a principal-agent framework, Hermalin and Weisbach (1998) remark that performance offers information about the CEO's ability, and based on this observable measure the board evaluates the quality of the CEO. In addition, the board estimates the CEO's ability, which represents a proxy of the expected performance. Therefore, CEO turnover is a control mechanism linked to the monitoring task of the board (Laux 2010). In this context, efficient managers signal their superior skills by introducing policies that improve the monitoring over their portfolios, which decreases the probability of financial losses. Conversely, poorly performing managers are more likely to incur higher losses due to ineffective loans’ monitoring.

Banking literature on these risk- and control-related issues is two folded. On the one hand, there are studies that link risk with performance. To name just a few, analyses exist for the US (Hughes and Mester 1998), Japan (Altunbas et al. 2000; Barros et al. 2012), South Korea (Park and Weber 2006; Banker et al. 2010), Taiwan (Hsiao et al. 2010), Brasil (Tabak et al. 2011), for various Latin American countries (Yildirim and Philippatos 2007) or for 87 countries around the world (Lozano-Vivas and Pasiouras 2010). Main findings indicate that the level of financial capital is positively related to efficiency and that using risk variables does not contribute to explaining scale inefficiencies (Hughes and Mester 1998; Altunbas et al. 2000). Evidence also suggests that NPL- 
used as a measure of credit risk-negatively influence efficiency (Barros et al. 2012). Moreover, Yildirim and Philippatos (2007) and Lozano-Vivas and Pasiouras (2010) find that changes in regulatory frameworks jointly with introducing monitoring tools help improving efficiency levels.

On the other hand, banks face problems derived from inefficient monitoring (or control practices in general) since conflicts of interests may appear between principals, managers and depositors. Hence, research also scrutinises the relations between corporate governance mechanisms and performance. Nonetheless, similarly to the case of the link between risk and performance, few studies focus on the role of corporate governance on bank performance (Simpson and Gleason 1999; Macey and O’Hara 2003; Crespí et al. 2004; Laeven and Levine 2009).

To the best of our knowledge, these two research streams do not converge. In this paper we propose a way to assess bank performance in the presence of risk, and introduce executive turnover to further isolate the effect that changes in management practices have on future performance. CEO replacements are crucial because they are often linked to the monitoring task of the board. There is a general consensus that the probability of CEO turnover is negatively related to performance, and that the board replaces a poorly performing CEO to enhance performance (Huson et al. 2001; Hermalin and Weisbach 2003). For these cases, existing findings suggest that improvements in shareholders' wealth and firm operations follow CEO turnover (Denis and Denis 1995; Huson et al. 2004).

At this point, it is important to notice that we focus on the origin of the successor rather than the type of departure. Even if distinguishing between voluntary and unexpected replacements is important, Hermalin and Weisbach (2003) and Huson et al. (2004) report that a voluntary CEO departure can be due to retirement or the acceptance of an external position. As a result, voluntary departures are not a signal of poor management or performance, and consequently, firms' future performance is expected to show smaller variations when compared with unexpected departures. In this way, not identifying the type of departure only adds noise to the proxy measure of executive turnover, which could lead to a downward biased estimate of performance changes.

Concerning the type of successor, banks can appoint an insider or outsider CEO. When banks decide to promote an internal candidate, no significant improvements in performance are expected, since the new CEO is more likely to continue with the existing policies and routines. Alternatively, under the improved management hypothesis, a bank hires an outsider CEO to seek organisational change driven by this new agent who is not influenced by current mechanics. In this case, management quality is expected to enhance since outsiders usually have stronger incentives to prove their skills to the board by introducing new practices that potentially improve performance (Zhang and Rajagopalan 2010). Accordingly, Borokhovich et al. (1996), Farrell and Whidbee (2003) or Huson et al. (2004) report significant positive changes in firm performance when CEO departures were followed by the appointment of a CEO from outside the firm. 


\section{A proposal for assessing efficiency in the presence of risk}

When dealing with multiple inputs yielding multiple outputs, efficiency literature usually employs DEA-based frontier methods grounded in economic production theory (see, e.g., Ray (2004) or Cooper et al. (2011)). DEA is a non-parametric technique that approximates the true but unknown technology, imposes no restrictions on the sample distribution, and does not require input or output prices. Efficient decision-making units shape the best practice frontier, while for the rest of units DEA computes an inefficiency score indicating their distance to the frontier. Thus, DEA is a complex benchmarking technique, where all analysed units are compared against each other. Note that the frontier is considered to be the best available technology (i.e. it is an approximation of the real technology), and therefore the model projects inefficient units on it without proposing to improve existing best practices.

Various DEA applications made way for developing diverse efficiency measures (see Ray (2004), Cooper et al. (2011) or the comprehensive review in Cook and Seiford (2009)). The growing awareness of the utility of DEA jointly with the need of well-defining inputs and outputs vectors led to new streams of research that not only account for inputs and desirable (good) outputs, but also accommodate undesirable (bad) outputs. The joint treatment of good and bad outputs is a current trend in the banking literature (Park and Weber 2006; Fukuyama and Weber 2010; Barros et al. 2012), and - to name just another research stream - is widely employed for environmental studies (Färe et al. 2004; Kumar 2006; Sueyoshi and Goto 2011).

Let us first specify a general technology with good and bad outputs, which will subsequently be adapted to the particular case of the banking industry. As a baseline we define $\mathbf{x}=\left(x_{1}, \ldots, X_{N}\right) \in R_{+}^{N}, \mathbf{y}=\left(y_{1}, \ldots, y_{M}\right) \in R_{+}^{M}$ and $\mathbf{b}=\left(b_{1}, \ldots, b_{J}\right) \in R_{+}^{J}$ as the vectors of inputs, good outputs and bad outputs, respectively. These form the technology $T$, representing the set of all output vectors (y and $\mathbf{b})$ that can be produced using the input vector $(\mathbf{x}): T=\{(\mathbf{x}, \mathbf{y}, \mathbf{b})$ : $\mathbf{x}$ can produce $(\mathbf{y}, \mathbf{b})\}$. Obviously, if one does not differentiate between good and bad outputs, then the input vector (x) would produce a total output vector given by the sum of vectors $\mathbf{y}$ and $\mathbf{b}$.

When modelling DEA with good and bad outputs, technology ( $T$ ) usually assumes convexity, strong disposability of inputs and good outputs, and weak disposability of bad outputs. ${ }^{1}$ The strong disposability constraint imposes that a larger quantity of inputs can be used to produce the same quantity of outputs, or fewer good outputs and the same quantity of bad outputs can be produced from a certain level of inputs. The weak disposability constraint indicates that to reduce bad outputs (a costly process), a unit must produce less total outputs, given fixed input levels. Best practice frontiers are shaped for each year by $k=1, \ldots, K$ units in the corresponding period.

\footnotetext{
${ }^{1}$ Strong disposability of inputs and good outputs implies that if $(x, y, b) \in T, 0 \leq y^{\prime} \leq y$ and $x^{\prime} \geq x$ (for each component) then $\left(x^{\prime}, y^{\prime}, b\right) \in T$. Weak disposability of bad outputs and good outputs implies that if $(x, y, b) \in T$ then $(x, \theta y, \theta b) \in T$ for $0 \leq \theta \leq 1$.
} 
Yet another assumption, many times treated superficially, relates to the returns to scale. While assuming constant returns to scale has attractive properties, existing literature signalled that on most occasions the true technology experiences variable returns to scale (VRS). For instance, Chambers and Pope (1996) argued that restricting the returns to scale to constant should be avoided unless one analyses firms in long-run equilibrium. Moreover, managerial-oriented assessments should report pure technical efficiency scores. This is because, contrary to technical efficiency under constant returns to scale, pure technical efficiency (VRS) captures outcomes linked to managerial practices and reforming firm operations.

Defining a VRS technology that allows some outputs to be weakly disposable while other outputs are strongly disposable can be problematic due to computational issues. This technology was accurately represented by Kuosmanen (2005). Furthermore, Kuosmanen's specification is the VRS technology that most closely incorporates all observed activities and satisfies strong disposability of inputs and good outputs, weak disposability of bad outputs, and convexity (Kuosmanen and Podinovski 2009; Podinovski and Kuosmanen 2011). It can be defined as follows:

$$
\begin{aligned}
T=\{(x, y, b): & \sum_{k=1}^{K} \theta^{k} \lambda^{k} y_{m}^{k} \geq y_{m}^{k^{\prime}} \geq 0, \quad m=1,2, \ldots, M \\
& \sum_{k=1}^{K} \theta^{k} \lambda^{k} b_{j}^{k}=b_{j}^{k^{\prime}}, \quad \mathrm{j}=1,2, \ldots, J \\
& \sum_{k=1}^{K} \lambda^{k} x_{n}^{k} \leq x_{n}^{k^{\prime}}, \quad \mathrm{n}=1,2, \ldots, N \\
& \sum_{k=1}^{K} \lambda^{k}=1 \\
& \lambda^{k} \geq 0, \quad k=1,2, \ldots, K \\
& \left.0 \leq \theta^{k} \leq 1, \quad k=1,2, \ldots, K\right\} .
\end{aligned}
$$

Note that (1) develops the traditionally employed technology that does not differentiate between good (y) and bad (b) outputs (i.e. a total output vector is produced using the input vector $\mathbf{x}$ ), and assumes convexity, VRS, and strong disposability of inputs and outputs. To reach this basic technology one just needs to completely remove both the bad outputs constraint and the abatement factor $(\theta)$ from expression (1). When modelling both good and bad outputs, this abatement factor enables the contraction of bad outputs only if accompanied by the contraction of good outputs.

However, depending on the analysed industry, bad outputs may not be linked to all good outputs. When dealing with environmental performance, as exemplified by Podinovski and Kuosmanen (2011), one can think that a good output such as steel is always linked to a bad output, such as harmful emissions. Nevertheless, in other sectors such as banking or service industries not all good outputs are related to the bad outputs. In our case, banks grant loans, which may prove to be good (performing) or bad (non-performing, i.e., NPL) depending on the intensity of monitoring and customers' behaviours. That is, the composition of the total loans is unaffected by other assets such as investment portfolios. To incorporate all these banking characteristics in efficiency analyses there isto the best of our knowledge-no formalised modelling of NPL, as most existing studies assume the 
joint production of all bank outputs (see, e.g., Park and Weber (2006), Fukuyama and Weber (2010) or Barros et al. (2012)).

We thus propose to separate the vector of good outputs (y) into two vectors of good outputs linked to bad outputs $\left(\mathbf{u}=\left(u_{1}, \ldots, u_{I}\right) \in R_{+}^{I}\right)$ and good outputs not linked to bad outputs $\left(\mathbf{v}=\left(v_{1}, \ldots, v_{L}\right) \in R_{+}^{L}\right)$. That is, the production of the good output vector (u) implies that bad output (b) is also produced. Nonetheless, when producing the good output vector (v) there need not be any production of bad output (b). By using the abatement factor $(\theta)$ only for modelling the relation between bad outputs and their related good outputs, the technology is now:

$$
\begin{aligned}
T=\{(x, u, v, b): & \sum_{k=1}^{K} \theta^{k} \lambda^{k} u_{i}^{k} \geq u_{i}^{k^{\prime}} \geq 0, \quad \mathrm{i}=1,2, \ldots, I \\
& \sum_{k=1}^{K} \theta^{k} \lambda^{k} b_{j}^{k}=b_{j}^{k^{\prime}}, \quad \mathrm{j}=1,2, \ldots, J \\
& \sum_{k=1}^{K} \lambda^{k} v_{l}^{k} \geq v_{l}^{k^{\prime}}, \quad \mathrm{l}=1,2, \ldots, L \\
& \sum_{k=1}^{K} \lambda^{k} x_{n}^{k} \leq x_{n}^{k^{\prime}}, \quad \mathrm{n}=1,2, \ldots, N \\
& \sum_{k=1}^{K} \lambda^{k}=1 \\
& \lambda^{k} \geq 0, k=1,2, \ldots, K \\
& \left.0 \leq \theta^{k} \leq 1, k=1,2, \ldots, K\right\} .
\end{aligned}
$$

Inefficiency is measured using the directional distance function proposed by Chambers et al. (1996). In its general form, the directional distance function seeks to simultaneously expand all types of good outputs, and contract bad outputs and inputs. Letting $\mathbf{g}=\left(g_{x}, g_{u}, g_{v}, g_{b}\right)$ be a directional vector, this function can be written as:

$$
\left.D\left(x^{k^{\prime}}, u^{k^{\prime}}, v^{k^{\prime}}, b^{k^{\prime}}\right)=\max \left\{\delta: x^{k^{\prime}}-\delta g_{x}, u^{k^{\prime}}+\delta g_{u}, v^{k^{\prime}}+\delta g_{v}, b^{k^{\prime}}-\delta g_{b}\right) \in T^{k}\right\} \text {. }
$$

However, the values of the directional vector $\mathbf{g}=\left(g_{x}, g_{u}, g_{v}, g_{b}\right)$ must be assigned. One could define $\mathbf{g}=$ $(1,1,1,1)$ to obtain the maximum unit expansion in all good outputs and simultaneous unit contraction in bad outputs and inputs. Another of the many possibilities may be a vector $\mathbf{g}=(x, 0,0,0)$ that would yield the percentage contraction in inputs, holding all outputs fixed.

For this paper, the vector $\mathbf{g}=(x, u, v, b)$ is used, similarly to the proportional distance function proposed by Briec (1997). Following equation (3), this specification estimates the simultaneous expansion in all good outputs, contraction in bad outputs and contraction in inputs. Since we assess bank performance from a managerial control perspective, estimations are relevant at bank level. That is, the selected directional vector is in accordance with our objectives and framework as it allows taking into account bank specific characteristics.

This directional distance function can be computed as the solution to a linear programme. The non-linear technology in (2) can be linearised using the substitution from Kuosmanen (2005): $z^{k}=\theta^{k} \lambda^{k}$ and $\mu^{k}=\left(1-\theta^{k}\right) \lambda^{k}, \forall k$ so that $z^{k}+\mu^{k}=\lambda^{k}$. Next, to model the technology in (2) and compute expression (3) expanding all good outputs and contracting all bad outputs, one must solve: 


$$
\begin{array}{ll}
D\left(x^{k^{\prime}}, u^{k^{\prime}}, v^{k^{\prime}}, b^{k^{\prime}}\right)=\max \delta \\
\text { s.t. } & \sum_{k=1}^{K} z^{k} u_{i}^{k} \geq u_{i}^{k^{\prime}}+\delta u_{i}^{k^{\prime}}, \quad \mathrm{i}=1,2, \ldots, I \\
& \sum_{k=1}^{K} z^{k} b_{j}^{k}=b_{j}^{k^{\prime}}-\delta b_{j}^{k^{\prime}}, \quad \mathrm{j}=1,2, \ldots, J \\
& \sum_{k=1}^{K}\left(z^{k}+\mu^{k}\right) v_{l}^{k} \geq v_{l}^{k^{\prime}}+\delta v_{l}^{k^{\prime}}, \quad \mathrm{l}=1,2, \ldots, L \\
& \sum_{k=1}^{K}\left(z^{k}+\mu^{k}\right) x_{n}^{k} \leq x_{n}^{k^{\prime}}-\delta x_{n}^{k^{\prime}}, \quad \mathrm{n}=1,2, \ldots, N \\
& \sum_{k=1}^{K}\left(z^{k}+\mu^{k}\right)=1 \\
& z^{k}, \mu^{k} \geq 0, k=1,2, \ldots, K .
\end{array}
$$

An efficient unit, situated on the best practice frontier, will have $D\left(x^{k^{\prime}}, u^{k^{\prime}}, v^{k^{\prime}}, b^{k^{\prime}}\right)=0$, whereas values of $D\left(x^{k^{\prime}}, u^{k^{\prime}}, v^{k^{\prime}}, b^{k^{\prime}}\right)>0$ show the degree of inefficiency of the analysed unit. Figure 1 presents a simplified representation of the directional distance function by illustrating the two-dimensional relation between the linked good and bad outputs. It also shows the difference between this function and the more traditional Shephard output distance function.

[Figure 1 about here]

On the one hand, the output distance function expands both linked good and bad outputs simultaneously, placing the output vector A on the boundary point C. On the other hand, the directional distance function starts at point $\mathrm{A}$ and scales taking a direction for increasing good outputs and decreasing bad outputs to point B on the boundary. Therefore, $\delta u^{k^{\prime}}$ is added to the linked good output and $\delta b^{k^{\prime}}$ is subtracted from the bad output. Additionally, even if not observable in the figure, the good outputs not linked to the bads are expanded by $\delta v^{k^{\prime}}$, whereas inputs are contracted by $\delta x^{k^{\prime}}$.

\section{The Costa Rican banking industry: Deregulation processes and consolidation}

As in other developing economies, the deregulation of the Costa Rican banking sector aimed at improving monitoring activities as well as enhancing banks' competitiveness (Yildirim and Philippatos 2007). Before 1980, Costa Rican banks were tightly regulated in terms of interest rates and activities. Reforms started in 1984 by liberalising interest rate pricing policies. In 1992, the Central Bank removed the demand deposit monopoly to allow private banks to capture resources from the population. Also, banks were allowed to grant loans and operate in foreign currency (US dollars).

In 1995 further reforms improved supervision tasks and the transparency of financial firms (IMF 2003). Due to increased market competition and the complexity of the banking system, the Central Bank created an independent supervisory agency to monitor banks, the Superintendent of Financial Entities (SUGEF). Similar policies were adopted in the securities and pension funds markets, where monitoring agencies were introduced. In 1997, the National Council of Supervision of the Financial System was created. This is the main supervisory authority of the financial system, which monitors and coordinates the superintendents of the banking system, the stock market, and the pension fund operators (IMF 2003). Thus, full disclosure of bank activities started in 1997. 
One last reform took place in 2001, when SUGEF introduced the CAMELS rating framework to further enhance monitoring over financial institutions (IMF 2003). This scheme facilitates monitoring over six major aspects of financial firms: capital adequacy, asset quality, management, earnings, liquidity, and sensitivity to market risk (SUGEF 2000). SUGEF actively monitors all financial firms, including: state-owned commercial banks, private banks, mutual banks, cooperative banks, financial conglomerates, financial (non-banking) firms, credit unions and currency exchange offices. Yet, for the purposes of this paper, and given technology differences, we focus the analysis on those banks that operate under the same market conditions: the state-owned commercial banks, private banks, mutual banks and cooperative banks.

First, state-owned banks are controlled by the Costa Rican government and, according to the financial regulations, they are considered independent firms since politicians do not influence their managerial decisions. This group attracted $54 \%$ of the deposits and $48 \%$ of the loans in 2012 . The second group includes private banks. In 2012, this group controlled 29\% of all deposits and 36\% of the loans. The third group are the mutual banks, which in 2012 had 7\% and 5\% of the deposits and loans, respectively. Their deposits are, similarly to the state-owned banks, guaranteed by the government. The last group consists of cooperative banks, which, even if owned by their members, offer their services to any type of customer. In 2012 these firms accounted for $10 \%$ and $11 \%$ of the deposits and loans, respectively.

At this point some considerations on sample characteristics are in order. First, it is worth noting that all Costa Rican banks operate under the same regulatory regime, and their capacity is unrestricted in terms of financial activities. Second, according to the financial regulations, banks' boards have to be fully composed of outside members. Consequently, the positions of Chairman and CEO cannot be vested in the same person. This is consistent with the concerns of several corporate governance activists about the importance of the firm's leadership structure. In this sense, Fama and Jensen (1983) and Jensen (1993) claim that concentration of decision and control rights in one individual reduces the board's effectiveness and leaves internal control mechanisms in a weaker position for disciplining poor managers. In conclusion, financial laws not only restrict the composition of the board of directors, but also introduce transparency mechanisms that facilitate the access to detailed information on financial operations and organisational architecture.

\section{Sample, variables and analysis stages}

\subsection{Sample and Variables}

Data come from the Costa Rican Central Bank, are publicly available, and comprise information for all banks operating in the industry during 1998-2012. This period witnessed a limited number of entries and exits, and, given the similar objectives of the studied financial institutions (see Section 4), we decided to use an unbalanced panel that encompasses all state, private, mutual and 
cooperative banks that participate in the market. Thus, the total analysed sample comprises 663 firmyear observations. ${ }^{2}$

Banking efficiency literature identifies two main approaches for evaluating financial institutions (see the surveys of Berger and Humphrey (1997), Goddard et al. (2001) or Fethi and Pasiouras (2010)). These are the production and intermediation approaches. Under the production approach banks are viewed as producers of both deposits and loans. In this case inputs are labour and capital. The intermediation approach considers that banks attract deposits and purchased funds that are transformed into loans and financial investments. Hence, in this second definition, one should also introduce funds (i.e. the raw material to transform) as inputs.

This study utilises the intermediation approach, which is thought to be better suited to the currently deregulated banking activities (Berger and Humphrey 1997; Goddard et al. 2001). Apart from traditional balance sheet variables (e.g. deposits, assets, securities or loans), one should also account for other non-balance sheet dimensions. We partly capture these dimensions by adding gains from fee-based operations, which can be considered a non-traditional output (Illueca et al. 2009). Moreover, due to the purpose of the study and the modelling of outputs, total loans are divided into performing (good) loans and non-performing (bad) loans. Table 1 presents the mean values of inputs and outputs for the analysed period. The selected inputs are: $\left(x_{1}\right)$ deposits, $\left(x_{2}\right)$ fixed assets, $\left(x_{3}\right)$ wages, and $\left(x_{4}\right)$ general administrative expenses. These thoroughly express funding, capital, labour and operating costs, respectively. Outputs are: $(u)$ performing loans, $(b)$ non-performing loans (NPL), $\left(v_{1}\right)$ securities (investment portfolio), and ( $\left.v_{2}\right)$ service fees (non-interest income).

[Table 1 about here]

Performing and non-performing loans are separated from the total loans using the rules set by the SUGEF. Specifically, NPL (be they mortgages, regular loans or corporate loans) are those past due for at least 90 days. These two output categories represent the linked good (u) and bad (b) outputs, as banks inevitably produce them simultaneously. In fact, NPL reflect credit risk and data show only positive values for both performing and non-performing loans. However, credit and the other considered outputs are mutually exclusive. Therefore, securities and service fees (v) represent banking dimensions unrelated with loans and are introduced as good outputs not linked to the undesirable output (NPL).

Efficiency scores derived from our proposal in equation (4) are interpreted jointly with accounting ratios to further reveal their managerial implications. Most of these discussions are carried out at bank-level, whereas we also briefly discuss some average industry-level effects of risk on performance. Descriptive statistics for the accounting ratios and risk variables are presented in Table 2. Accounting measures evaluate economic performance, and are specified through return on assets (ROA) computed as the ratio of profit to total assets, and the net interest margin (NIM), which is the

\footnotetext{
${ }^{2}$ Section 5.2 explains how data are used to construct the best practice frontiers.
} 
difference between interest income and interest expense relative to total assets. Risk is measured via two ratios commonly used in previous studies (Altunbas et al. 2000; Park and Weber 2006; Banker et al. 2010; Barros et al. 2012). First, for our main bank-level analysis, the NPL ratio is given by nonperforming loans relative to total loans. Second, for supplementary industry-level interpretations, a proxy variable for the capital adequacy ratio (CAR) is calculated as equity plus risk-weighted reserves divided by total assets.

[Tables 2 and 3 about here]

For the analysis related to executive replacements, Table 3 presents the frequency of CEO turnover during 2000-2010 and the type of the incoming manager. We consider that a CEO turnover corresponds to a specific period only if the name of the top manager changes in two consecutive years. Thus, CEO turnover is captured by a dummy variable that takes the value of one if the top executive manager was replaced, and zero otherwise. In addition, two dummy variables take the value of one if the successor is from inside or outside the bank, and zero otherwise. An internal promotion is identified if the new CEO was part of either the board or the top management team in the year prior to her appointment.

\subsection{Frontier specifications and analysis stages}

We first compute the efficiency scores following the proposal in equation (4) and using the inputs and outputs specified in Section 5.1. There are, nonetheless, some more considerations necessary. First, literature expresses concerns linked to production possibilities. One example is found in Kumar and Rusell (2002), who point out that the true but unobservable frontier should include the knowledge accumulated from previous periods. Second, pitfalls may appear in the presence of a reduced number of observations and a relatively high number of input and output dimensions.

Both concerns are addressed by using technology specifications including sequential reference sets (Tulkens and Vanden Eeckaut 1995). A sequential reference set implies that the current period technology depends not only on contemporary observations of inputs and outputs, but also on combinations from all previous periods. That is, the technology (i.e. the efficiency frontier) is constructed from all observed best practices of banks in the sample (for empirical applications see, e.g., Park and Weber (2006) or Banker et al. (2010)). When listing results, scores are reported only for the year under analysis. However, when the analysed period is extensive, sequential frontiers including all pervious periods can lead to efficiency estimates that are difficult to interpret, or even unreliable. This becomes even more so when the analysis includes both progress and regress periods.

Taking into account these concerns jointly with our bank-level focus, we construct frontiers that match control systems. In managerial settings it makes sense to benchmark against best practices from the current period and also to use feedback from the relevant previous periods (Kaplan and Atkinson 2000). Indeed, the benchmarking literature usually states that managerial best practices used 
as targets for control should be relevant, attainable and - to the possible extent-observable (Camp 1995). On many occasions, frontier targets from the recent previous periods are the objectives employed for control activities, while the current year benchmarks can help verifying whether the bank is currently a good practice. In turn, the current period results and targets become objectives for managerial control in the near future.

To match the managerial control setting described above, we use a three-year "sequential window" that reports scores for the analysed (third) year. Furthermore, for each new period we drop the oldest one, so that the frontier is always shaped by three periods. This is a combination between the sequential frontier approach of Tulkens and Vanden Eeckhaut (1995) and the more traditional window analysis of Charnes et al. (1984). That is, we apply the window analysis rationale of nested relevant periods, but report the results only for the last year, similar to the sequential sets of Tulkens and Vanden Eeckhaut (1995). Note that this approach is natural from a strategic management perspective, as it follows the rationale of mid-term planning and control (see, e.g., Grant (2008)).

The sensitivity of the efficiency scores is scrutinised by estimating "sequential windows" of different extensions and the usual sequential approach that includes all previous years. Although the magnitude of the scores changes (by construction) the overall tenor of the results and general interpretations do not. For the main discussion, we follow the above managerial rationale of a threeyear "sequential window". Results are reported yearly for the period 1998-2012, whereas the reference technology includes the analysed year jointly with the previous two.

These efficiency scores have a managerial interpretation not only due to the benchmarking for monitoring bank activity, but also because of the particularities of the proportional distance function employed in equation (4). We reach bank-level interpretations that are not always easily aggregated to industry-level results, which are more relevant to regulators (see, e.g., Färe and Grosskopf (2004)). A supplementary industry-level analysis - which we detail in the Appendix and only briefly discuss in Section 6-provides some effects of risk on bank performance.

Finally, we employ our proposal to examine the effect of CEO turnover on future performance. This special case provides an ideal illustration of how the benchmarked efficiency scores that account for risk can be used for corporate governance purposes. We track performance changes over time spans of five years centred on the replacement year. In line with our theoretical underpinnings, we distinguish between the effects of appointing an outsider or insider CEO. Moreover, following Huson et al. (2004), we control for potential problems related to mean reversion of performance time-series. Details on this analysis and its results are presented in Section 6.2. 


\section{Results}

\subsection{Efficiency and accounting performance assessments}

Prior to reporting the efficiency assessments of our proposal in equation (4) we have run additional tests to confirm the influence of NPL and the significance of correctly introducing them in the banking technology. Specifically, we have computed efficiency scores following two alternative models. First, a traditional specification of the technology considers total loans as a desirable output, and therefore does not account for credit risk. The second alternative follows Kuosmanen (2005) and introduces NPL as a bad output linked to all good outputs (performing loans, securities and service fees). Bear in mind that in the introduction and the methodology-related sections we argue that thiseven if computationally correct-is not an accurate representation of the real banking technology. The Wilcoxon signed-rank test was used to detect the existing differences between our proposal and the two alternative models for the period 1998-2012. Outcomes clearly demonstrate that our proposal of linking NPL only to their corresponding good output attains efficiency estimates significantly different at $1 \%$ from the traditional model (Z-value -17.326) and the specification that links the bad output (NPL) to all good outputs (Z-value -4.582), respectively. This corroborates that our measure is not only closer to the real banking technology in theoretical terms, but also makes a difference for the interpretation of the results. Thus, in what follows the scores of our proposed NPL model (equation (4)) are analysed.

Keep in mind that scores of zero indicate efficient banks, whereas higher values point to the degree of inefficiency. For illustrative purposes, suppose that a fictitious bank has the following input and output vectors: $\left(x_{1}, x_{2}, x_{3}, x_{4}, u, v_{1}, v_{2}, b\right)=(600,310,200,150,400,320,70,100)$, and a corresponding efficiency score $\delta=0.03$. To operate efficiently, this bank should expand performing loans $(u)$ by $400 \times 0.03=12$, securities $\left(v_{1}\right)$ by $320 \times 0.03=9.6$, and service fees $\left(v_{2}\right)$ by $70 \times 0.03=$ 2.1. It should also simultaneously contract NPL $(b)$ by $100 \times 0.03=3$, while reducing deposits $\left(x_{1}\right)$ by $600 \times 0.03=18$, fixed assets $\left(x_{2}\right)$ by $310 \times 0.03=9.3$, wages $\left(x_{3}\right)$ by $200 \times 0.03=6$, and administrative expenses $\left(x_{4}\right)$ by $150 \times 0.03=4.5$.

Note that the interpretation of the efficiency score is bank-specific. This aspect is of crucial importance for the managerial control emphasis, as it accounts for the analysed banks' heterogeneous characteristics. The diverse directions of the proportional vector sometimes complicate the interpretation of industry-level results (Färe and Grosskopf 2004). In this context, the yearly average industry inefficiencies represent the evolution of the sector based on heterogeneous bank-specific inefficiencies. Thus, we interpret these average scores given our research perspective.

[Figure 2 and Table 4 about here]

In Figure 2 and Table 4 one can notice that, after peaking in 1999 (0.14), bank-level average inefficiencies generally decrease to the lowest level of 0.03 in 2006. This first half of the studied period is characterised by enhancements in the monitoring activities gradually introduced by the 
regulatory institutions (IMF 2003). Such reforms usually aim at enhancing banks' competitiveness and arguably banks need to adapt to the new market conditions (Park and Weber 2006; Lozano-Vivas and Pasiouras 2010). It may well be that the analysed banks anticipated these regulatory changes and adapted their internal control practices to the developing competitive environment. A potential reason for the relative lack of fluctuations in inefficiency scores at the start of the 2000s is that, due to more stable market conditions, reforms were not that drastic as in other Latin American countries (Yildirim and Philippatos 2007). During this first half of the analysed period there is a potential bubble effect. One may think that banks report lower proportions of NPL during 2003-2008 given this potential precrisis bubble, but it may also be the case that fewer bad debtors exist during growth periods. These mixed effects due to reforms, potential bubbles and the mere existence of bad debtors are extremely difficult to disentangle.

The second half of the period is dominated by the recent financial crisis. The number of bad debtors increases due to the economic downturn and around 2009-2010 the NPL ratio shows early2000s levels. Salient effects are observed in 2008 when reported bank-level inefficiency scores reach an average of 0.06. These levels remain roughly unchanged until 2010-2011. Towards the end of the time span, average bank-specific inefficiencies are of 0.05 , slightly lower than the main financial downturn period (2008-2010). Although one could expect an earlier and more accentuated recovery, this event was directly influenced by yet another series of regulatory pressures. On the background of the global economic crisis, financial capital requirements became more severe and aimed at, among other objectives, attaining Basel III capital adequacy levels (IMF 2013). Banks gradually adopted these conditions (mostly after 2009), which may have diverted attention of managers from internal operations to meeting the new market standards.

Taking a managerial control perspective, throughout the period banks can use the scores for performance evaluations. Given their comprehensive nature, which accounts for risk and includes distances to relevant competitors during mid-term strategic periods, the efficiency scores can be the basis of evaluating executives. This specific application is presented in Section 6.2.

[Figure 3 and Table 5 about here]

To provide some complementary industry-level interpretations, we complement the analysis with traditional accounting ratios. Results for ROA and NIM are shown in Figure 3 and Table 5. The insights from the efficiency scores are more difficult to observe in these one-dimensional accounting ratios that do not capture the different types of banking activities. ROA confirms to a great extent the results obtained from the efficiency assessment (see, e.g., the negative results for 1999, 2004 or the crisis period). However, ROA shows a more zigzag pattern and does not illustrate the slight improvement at the end of the analysed period. These differences may appear because ROA includes extraordinary results not related to the banks' core activity.

The NIM experiences a rather constant decrease between 2002 and 2009. This ratio could be considered a more useful profitability measure of current and future bank performance as its 
components (interest income and expenses) represent a large proportion of total bank revenues and costs (Van Hoose 2010). NIM decreases could signal enhanced market competition, which enforces performance and consequently narrows margin spreads (Bikker and Bos 2008). This is consistent with industry reforms introduced during the first half of the studied period (Yildirim and Philippatos 2007).

A supplementary industry-level analysis of the impact of risk on performance is presented in the Appendix. Results show that banks with higher NPL ratios exhibit higher inefficiency levels. ${ }^{3}$ This ratio is useful for internal monitoring, and results indicate that higher levels of NPL are costly for bank operations. Thus, enhancing monitoring levels over loans may be beneficial for bank efficiency. Alternatively, in the long-run high proportions of NPL could sometimes indicate higher risk taking. Incentives for risk taking may exist because equity owners could gain more if the bank experiences gains from risk taking (Van Hoose 2010). Findings for ROA and NIM confirm that higher NPL ratio levels are negatively related to short-run performance, in line with previous studies (Banker et al. 2010; Hsiao et al. 2010).

In the case of the CAR, results illustrate the positive effects of capital requirements on accounting results. While no effect of the CAR is reported for the efficiency scores, this ratio is positively related to ROA and NIM. Significant CAR results may signal that external monitoring helps banks obtain better accounting profitability results. The financial soundness of this variable reduces uncertainty, and allows banks to have better operational flexibility and market positions, which could reduce fund rising costs (Das and Ghosh 2006; Banker et al. 2010; Hsiao et al. 2010).

\subsection{Performance changes following executive turnover}

We now employ our proposal to examine the effect of CEO turnover on future performance. This analysis allows us to illustrate how efficiency scores can be used for corporate governance purposes. We scrutinise the performance changes shown by banks during a five years period centred on the CEO turnover year. For analytical purposes, we follow the procedure used by Denis and Denis (1995) and Huson et al. (2004) to correct for potential problems linked to mean reversion of performance time-series. Thus, annual performance values are calculated for two sub-periods around CEO turnover: from year -2 to year -1 (ex ante), and from year -1 to year +2 ex post executive replacement (see Table 6). In order to correctly examine the performance path followed by banks before and after CEO turnover, we only maintain in the sample those CEOs whose tenures cover the full period analysed (i.e. two years before replacement for the outgoing CEOs and two years postreplacement for the incoming ones) (see Table 3).

\footnotetext{
${ }^{3}$ Keep in mind that the NPL ratio is computed as NPL over total loans. In the efficiency model only NPL appear, and do so as an output. Furthermore, in DEA models, more or less of one output or input does not imply higher or lower inefficiency.
} 
To further corroborate the robustness of our results for the accounting ratios, we also estimate two alternative variables that account for market trends. These are median-adjusted ROA and NIM, which are obtained by subtracting, for each year, the median value of the corresponding measure for all firms in our sample. Note that DEA scores represent an efficiency assessment based on the technology of the sector (i.e. a benchmarking technique), and therefore adjusting to industry-median values is not appropriate. In this fashion, industry-adjusted performance changes following CEO turnover isolate the effect of CEO turnover on performance changes from variations attributable to the industry.

[Figures 4 and 5, and Table 6 about here]

Findings suggest that inefficiency tends to be lower in those banks that replaced the CEO (Figure 4). Figure 5 plots, for the five years period centred on the turnover year, the mean inefficiency values. Furthermore, it differentiates CEO turnover followed by appointing an insider (dotted line) or an outsider (dashed line) from the solid line that includes all CEO replacements. One can notice that the positive effect of CEO turnover on future performance is driven by those replacements followed by the appointment of a CEO from outside the bank. To the contrary, appointing an insider is associated with inefficiency increases.

Results in Panel A of Table 6 show that mean inefficiency around CEO turnover decreases from $0.08(-2$ to -1$)$ to $0.06(-1$ to +2$)$. This difference is significantly different from zero, and all the positive effect comes from appointing outsider CEOs. Indeed, when the incoming CEO is an outsider inefficiency significantly decreases from 0.09 ( -2 to -1$)$ to 0.07 ( -1 to +2$)$ and $57 \%$ of banks improve their efficiency. Similar findings are obtained for the accounting ratios (Panels B to E in Table 6). In the case of the ROA and NIM (both adjusted and unadjusted), performance significantly improves when appointing an outsider.

These results corroborate that CEO turnover is an important control mechanism, and that its effectiveness becomes especially relevant when the incoming manager is an outsider. This could signal not only that managers from outside are not influenced by banks' internal routines, but also that outsiders are more likely to introduce new practices and seek organisational changes, which are expected to improve operating performance (Farrell and Whidbee 2003; Huson et al. 2004). In this sense, outsiders may well have stronger incentives to prove the quality of their management skills to the board (Zhang and Rajagopalan 2010).

\section{Concluding remarks}

This paper takes a managerial control approach to develop a monitoring tool for assessing bank performance. Specifically, it proposes a multidimensional efficiency measure that accounts for the joint production of desirable outputs (performing loans, securities and service fees) and an undesirable output that represents credit risk (non-performing loans (NPL)). While some previous 
efforts to introduce risk in efficiency assessments exist, these have been scarce (see, e.g., the cost function approach of Hughes and Mester (1998) or Altunbas et al. (2000), or the use of NPL in Park and Weber (2006) and Barros et al. (2012)). Incorporating risk in efficiency analyses is increasingly important on the background of the financial crisis.

Our proposal extends Kuosmanen's (2005) specification to define the real banking technology that exhibits VRS and in which not all desirable outputs are linked to undesirable outputs. In this study, NPL are strictly linked only to that output category that affects their levels (performing loans), while the rest of outputs are not related to NPL. When modelling the technology, NPL are introduced as an endogenous risk measure that proxies the quality of monitoring over loans.

An empirical application illustrates how the proposed monitoring tool functions. The overall efficiency assessment considers the period 1998-2012, which includes two types of changes in the banking competitive environment. The first half of the period is characterised by gradual changes in the regulatory framework that aimed at enhancing monitoring activities. Results show general average bank-specific efficiency improvements over this period. ROA results mostly corroborate the efficiency scores. Also, the NIM slightly decreases, which could signal enhanced market competition and consolidation of banks (Bikker and Bos 2008). During this period-among other reforms-the CAMELS rating scheme was introduced. Findings suggest that banks anticipated this regulatory change and adapted internal practices to the developing market conditions (Grifell-Tatjé and Lovell 1999; Park and Weber 2006; Lozano-Vivas and Pasiouras 2010).

The second half of the analysed period is mostly dominated by the current financial crisis. After experiencing decreases during 2006-2008, average bank-specific efficiency remains relatively unchanged after 2008, with minor improvements towards the end of the period. Given the severe and extended financial crisis, this period witnessed the introduction of more rigorous financial capital requirements by national and international regulatory bodies (see, e.g., IMF (2013) for the Basel III requirements). Banks gradually adopted these conditions after 2009, which may have swayed managers towards the enforcement of the new market standards rather than attaining superior efficiency by improving internal operations.

Our comprehensive efficiency measure accounts for risk and includes distances to relevant competitors during mid-term strategic periods. From a managerial control perspective, these characteristics enhance the efficiency scores' attractiveness for corporate governance purposes. If internal and external control mechanisms work properly, efficiency scores should capture performance changes following CEO turnover events. We find that changes in top executives lead to greater efficiency and accounting performance. This effect mainly holds when the incoming CEO is an outsider. According to the improved management hypothesis, this could indicate that outsiders have a clearer influence on performance since they introduce new organisational practices (Huson et al. 2004). In addition, managers appointed from outside have stronger incentives to prove their potential quality to the board by showing their management skills (Zhang and Rajagopalan 2010). 
There are a series of limitations to our study that, in turn, represent avenues for future research. Our proposal takes a managerial control approach to evaluating bank efficiency. Yet, there are some trade-offs between this bank-specific approach and more industry-oriented analyses. Future research could extend the analysis to include issues of interest to policy makers and regulators. First, by using homogenous directions of the directional vector-instead of a proportional distance function based on observed bank-specific input and output vectors-efficiency scores can be easily aggregated and interpreted at industry level (see aggregation issues in Färe and Grosskopf (2004)). In this case, vector directions can be chosen according to industry-level policy objectives and thus complement this study's managerial approach that uses bank-level scores.

Second, the effects of reforms or bank corporate governance characteristics (such as ownership type) could, alternatively to our proposal, be modelled using the concept of selective convexity introduced by Podinovski (2005). This method allows for individual judgements of each input and output according to the convexity assumption. Given that relaxing convexity is an attractive topic when discussing the benchmarking role of frontiers, this research avenue could be followed to enhance our corporate governance interpretations. Finally, new analyses could scrutinise scale efficiency issues. Banks operating under increasing, decreasing or constant returns to scale are potentially differently affected by risk and regulatory measures. This study can be a starting point towards analysing these issues from industry policy-making perspectives.

\section{References}

Altunbas, Y., Liu, M.H., Molyneux, P., Seth, R., 2000. Efficiency and risk in Japanese banking. Journal of Banking and Finance 24(10), 1605-1628.

Banker, R., Chang, H., Lee, S.Y., 2010. Differential impact of Korean banking system reforms on bank productivity. Journal of Banking and Finance 34(7), 1450-1460.

Banker, R., Chang, H., Natarajan, R., 2005. Productivity change, technical progress, and relative efficiency change in the public accounting industry. Management Science 51(2), 291-304.

Barros, C.P. Managi, S., Matousek, R., 2012. The technical efficiency of the Japanese banks: Nonradial directional performance measurement with undesirable output. Omega 40(1), 1-8.

Basel Committee on Banking Supervision, 2011. Range of methodologies for risk and performance alignment of remuneration. http://www.bis.org/publ/bcbs194.pdf, accessed 1 February 2012.

Berger, A.N., DeYoung, R., 1997. Problem loans and cost efficiency in commercial banks. Journal of Banking and Finance 21(6), 849-70.

Berger, A.N., Humphrey, D.B., 1997. The efficiency of financial institutions: International survey and directions for future research. European Journal of Operational Research 98(2), 175-212.

Bikker, J.A., Bos, J.W.B., 2008. Bank Performance. Routledge, New York. 
Borokhovich, K., Parrino, R., Trapani, T., 1996. Outside directors and CEO selection. Journal of Financial and Quantitative Analysis 31(3), 337-355.

Briec, W., 1997. A graph type extension of Farrell technical efficiency measure. Journal of Productivity Analysis 8(1), 95-110.

Camp, R.C., 1995. Business Process Benchmarking: Finding and Implementing Best Practices. ASQC Quality Press.

Chambers, R.G., Pope, R.D., 1996. Aggregate productivity measures. American Journal of Agricultural Economics 78(5), 1360-1365.

Charnes, A., Clark, C.T., Cooper, W.W., Golany, B., 1984. A developmental study of data envelopment analysis in measuring the efficiency of maintenance units in the US air forces. Annals of Operations Research 2(1), 95-112.

Cook, W.D, Seiford, L.M., 2009. Data envelopment analysis (DEA) - Thirty years on. European Journal of Operational Research 192(1), 1-17.

Cooper, W.W., Seiford, L.M., Zhu, J., 2011. Handbook on Data Envelopment Analysis. $2^{\text {nd }}$ ed. Springer, New York.

Crespí, R., García-Cestona, M., Salas, V., 2004. Governance mechanisms in Spanish banks: Does ownership matter? Journal of Banking and Finance 28(10), 2311-2330.

Das, A., Ghosh, S., 2006. Financial deregulation and efficiency: An empirical analysis of Indian banks during the post reform period. Review of Financial Economics 15(3), 193-221.

Denis, D.J., Denis, D.K., 1995. Firm performance changes following top management dismissals. Journal of Finance 50(4), 1029-1057.

Fama, E., Jensen, M., 1983. Separation of ownership and control. Journal of Law and Economics 26(2), 301-325.

Färe, R., Grosskopf, S., 2004. New Directions: Efficiency and Productivity. Kluwer, Boston.

Färe, R., Grosskopf, S., Hernandez-Sancho, F., 2004. Environmental performance: an index number approach. Resource and Energy Economics 26(4), 343-352.

Farrell, K.A., Whidbee, D.A., 2003. Impact of firm performance expectations on CEO turnover and replacement decisions. Journal of Accounting and Economics 36(1-3), 165-196.

Fethi, M.D., Pasiouras F., 2010. Assessing bank efficiency and performance with operational research and artificial intelligence techniques: A survey. European Journal of Operational Research 204(2), 189-198.

Fukuyama, H., Weber, W.L., 2010. A slacks-based inefficiency measure for a two-stage system with bad outputs. Omega 38(5), 398-409.

Goddard, J.A., Molyneux, P., Wilson, J.O.S., 2001. European Banking: Efficiency, Technology and Growth. Wiley, New York.

Grant, R.M., 2008. Contemporary Strategy Analysis. $6^{\text {th }}$ ed., Blackwell, Malden.

Greene, W., 2003. Econometric Analysis. $5^{\text {th }}$ ed., Upper Saddler River, New Jersey. 
Grifell-Tatjé, E., Lovell, C.A.K., 1999. Profits and productivity. Management Science 45(9), 11771193.

Hermalin, B., Weisbach, M., 1998. Endogenously chosen boards of directors and their monitoring of the CEO. American Economic Review 88(1), 96-118.

Hermalin, B., Weisbach, M., 2003. Board of directors as an endogenously determined institution: A survey of the economic literature. FRBNY Economic Policy Review 9(1), 7-26.

Hsiao, H.C., Chang, H., Cianci, A.M., Huang, L.H., 2010. First financial restructuring and operating efficiency: Evidence from Taiwanese commercial banks. Journal of Banking and Finance 34(7), 1461-1471.

Hughes, J.P., Mester, L.J., 1998. Bank capitalization and cost: Evidence of scale economies in risk management and signalling. Review of Economics and Statistics 80(2), 314-325.

Huson, M.R., Parrino, R., Starks, L.T., 2001. Internal monitoring mechanisms and CEO turnover: A long-term perspective. Journal of Finance 56(6), 2265-2297.

Huson, M.R., Malatesta, P., Parrino, R., 2004. Managerial succession and firm performance. Journal of Financial Economics 74(2), 237-275.

Illueca, M., Pastor, J.M., Tortosa-Ausina, E., 2009. The effects of geographic expansion on the productivity of Spanish savings banks. Journal of Productivity Analysis 32(2), 119-143.

International Monetary Fund (IMF), 2003. Costa Rica: Financial system stability assessment. IMF Country Report No. 03/103.

International Monetary Fund (IMF), 2013. Costa Rica: Selected issues. IMF Country Report No. $13 / 80$.

Jensen, M., 1993. Presidential address: The modern industrial revolution, exit and the failure of internal control systems. Journal of Finance 48(3), 831-880.

Kaplan, R.S., Atkinson, A.A., 2000. Advanced Management Accounting. 3th ed., Prentice Hall, Upper Saddle River.

Kumar, S., 2006. Environmentally sensitive productivity growth: A global analysis using MalmquistLuenberger index. Ecological Economics 56(2), 280-293.

Kumar, S., Russell, R., 2002. Technological change, technological catch-up and capital deepening: Relative contributions to growth and convergence. American Economic Review 92(3), 527-548.

Kuosmanen, T., 2005. Weak disposability in nonparametric productivity analysis with undesirable outputs. American Journal of Agricultural Economics 87(4), 1077-1082.

Kuosmanen, T., Podinovski, V.V., 2009. Weak disposability in nonparametric production analysis: Reply to Färe and Grosskopf. American Journal of Agricultural Economics 91(2), 539-545.

Laeven, L., Levine, R., 2009. Bank governance, regulation and risk taking. Journal of Financial Economics 93(2), 259-275.

Laux, V., 2010. Effects of litigation risk on board oversight and CEO incentive pay. Management Science 56(6), 938-948. 
Lozano-Vivas, A., Pasiouras, F., 2010. The impact of non-traditional activities on the estimation of bank efficiency: International evidence. Journal of Banking and Finance 34(7), 1436-1449.

Macey, J., O’Hara, M., 2003. The corporate governance of banks. FRBNY Economic Policy Review 9(1), 91-107.

McAllister, P.H., McManus, D., 1993. Resolving the scale efficiency puzzle in banking. Journal of Banking and Finance 17(2-3), 389-405.

Park, K.H., Weber W.L., 2006. A note on efficiency and productivity growth in the Korean banking industry, 1992-2002. Journal of Banking and Finance 30(8), 2371-2386.

Podinovski, V.V., 2005. Selective convexity in DEA models. European Journal of Operational Research 161(2), 552-563.

Podinovski, V.V., Kuosmanen, T., 2011. Modelling weak disposability in data envelopment analysis under relaxed convexity assumptions. European Journal of Operational Research 211(3), 577585.

Ray, S.C., 2004. Data Envelopment Analysis: Theory and Techniques for Economics and Operations Research. Cambridge University Press, New York.

Simar, L., Wilson, P., 2011. “Two-stage DEA: Caveat emptor”, Journal of Productivity Analysis 36(2), 205-218.

Simpson, G., Gleason, A., 1999. Board structure, ownership, and financial distress in banking firms. International Review of Economics and Finance 8(3), 281-292.

Sueyoshi, T., Goto, M., 2011. Methodological comparison between two unified (operational and environmental) efficiency measurements for environmental assessment. European Journal of Operational Research 210(3), 684-693.

Superintendent of Banks (SUGEF), 2000. Reglamento para juzgar la situación económica-financiera de las entidades fiscalizadas. Costa Rican Central Bank, Acuerdo SUGEF 24-00.

Tabak, B.M., Fazio, D.M., Cajueiro, D.O., 2011. The effects of loan portfolio concentration on Brazilian banks' return and risk. Journal of Banking and Finance 35(11), 3065-3076.

Tulkens, H., Vanden Eeckaut, P., 1995. Non-parametric efficiency, progress and regress measures for panel data: Methodological aspects. European Journal of Operational Research 80(3), 474-499.

Van Hoose, D., 2010. The Industrial Organization of Banking. Springer, Berlin.

Yildirim, H.S., Philippatos, G.C., 2007. Restructuring, consolidation and competition in Latin American banking markets. Journal of Banking and Finance 31(3), 629-639.

Zhang, Y., Rajagopalan, N., 2010. Once an Outsider, always an Outsider? CEO origin, strategic change, and firm performance. Strategic Management Journal 31(3), 334-346. 
Figure 1. The directional distance function with good and bad outputs

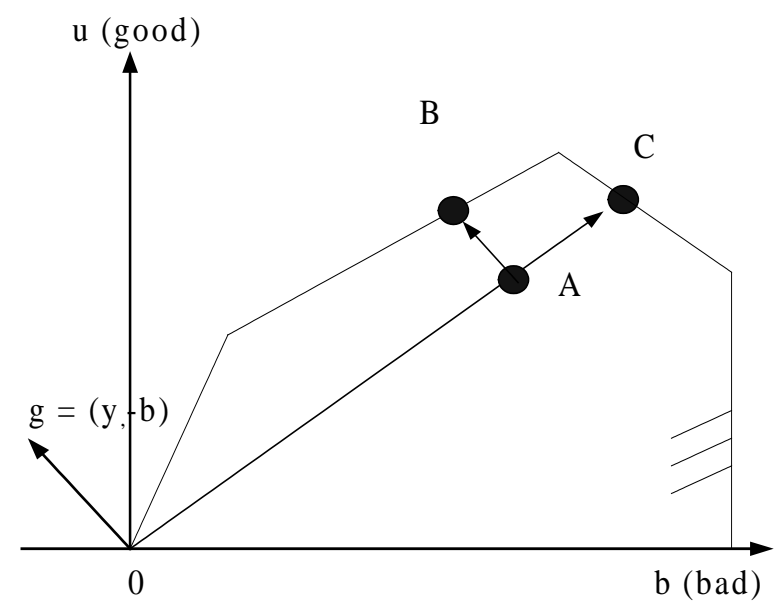

Figure 2. Efficiency scores: Mean values

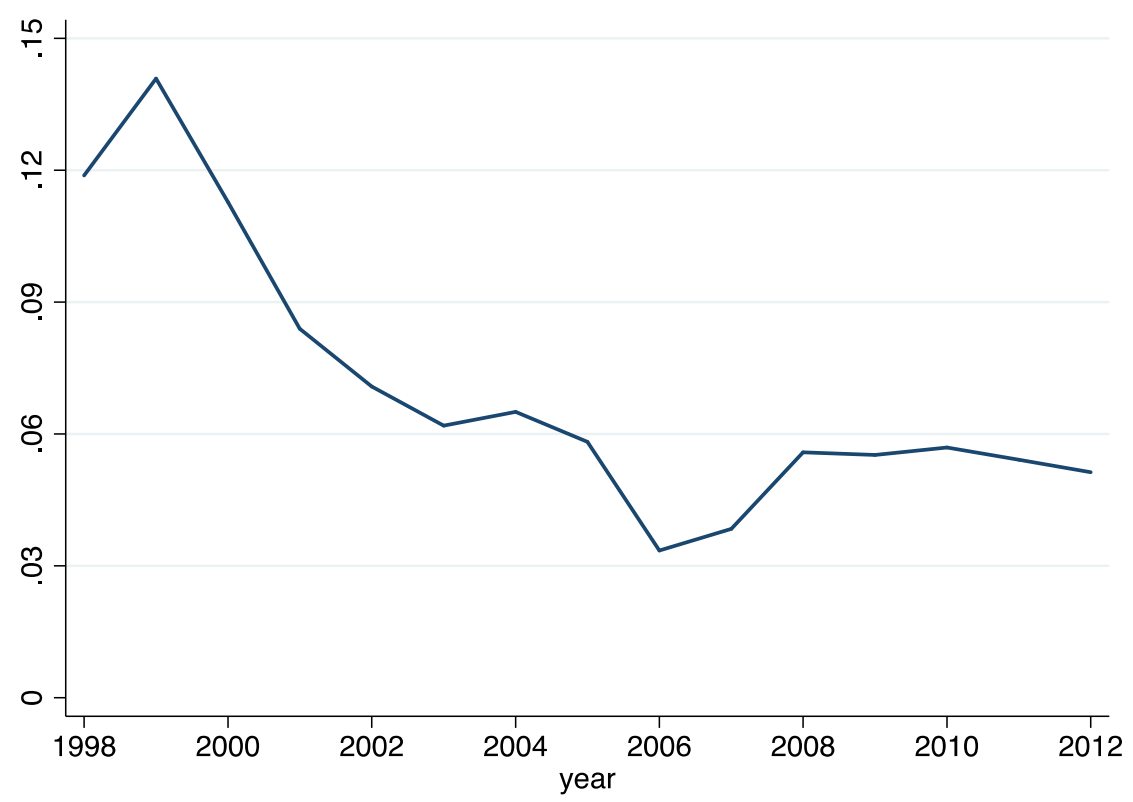


Figure 3. Accounting performance: Mean values

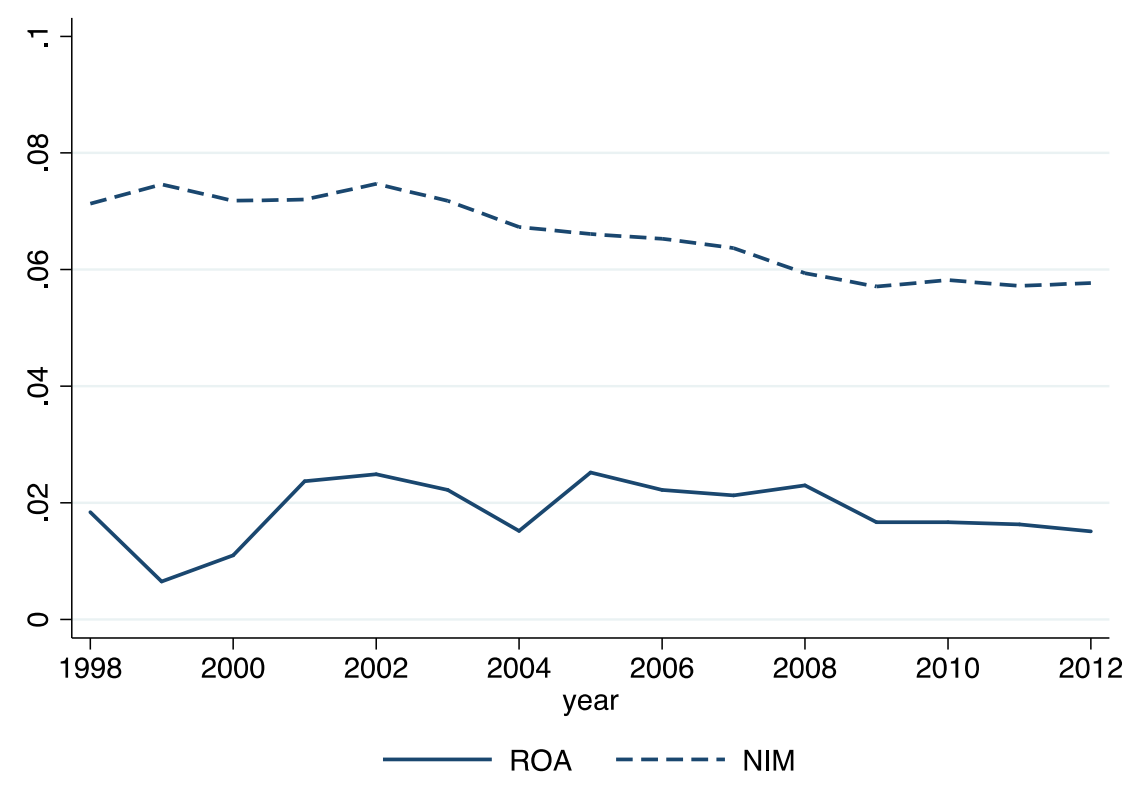


Figure 4. Efficiency changes around CEO turnover

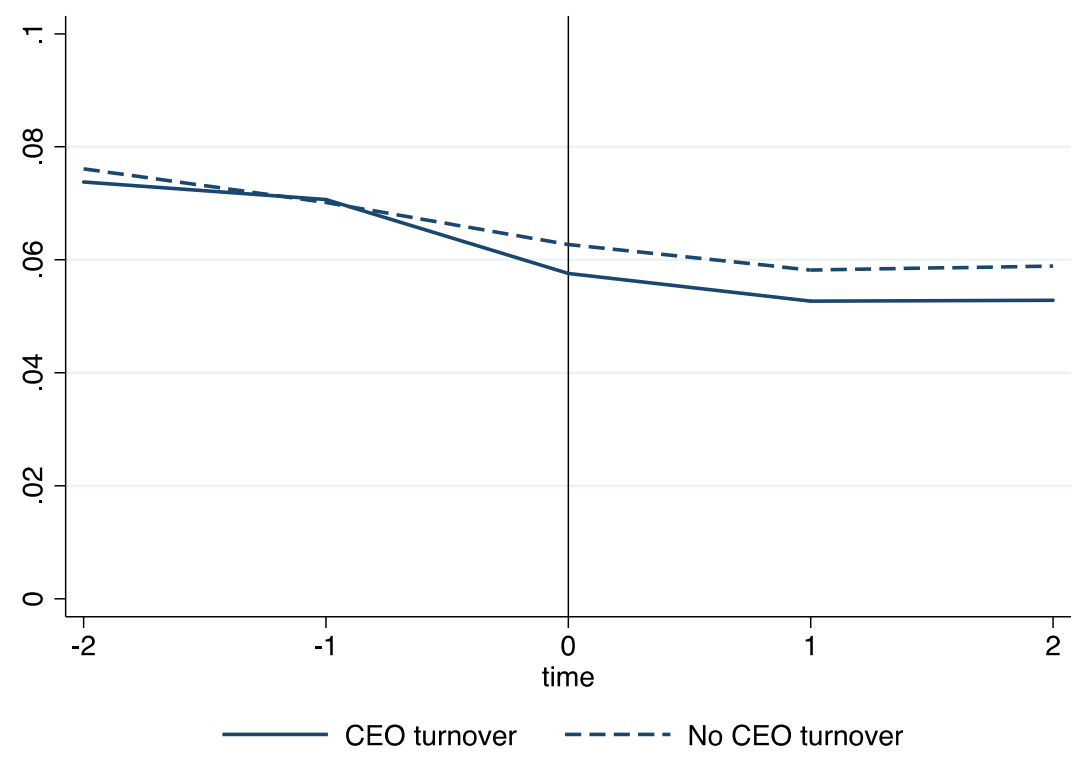

Figure 5. Efficiency changes around CEO turnover: Insiders vs. Outsiders

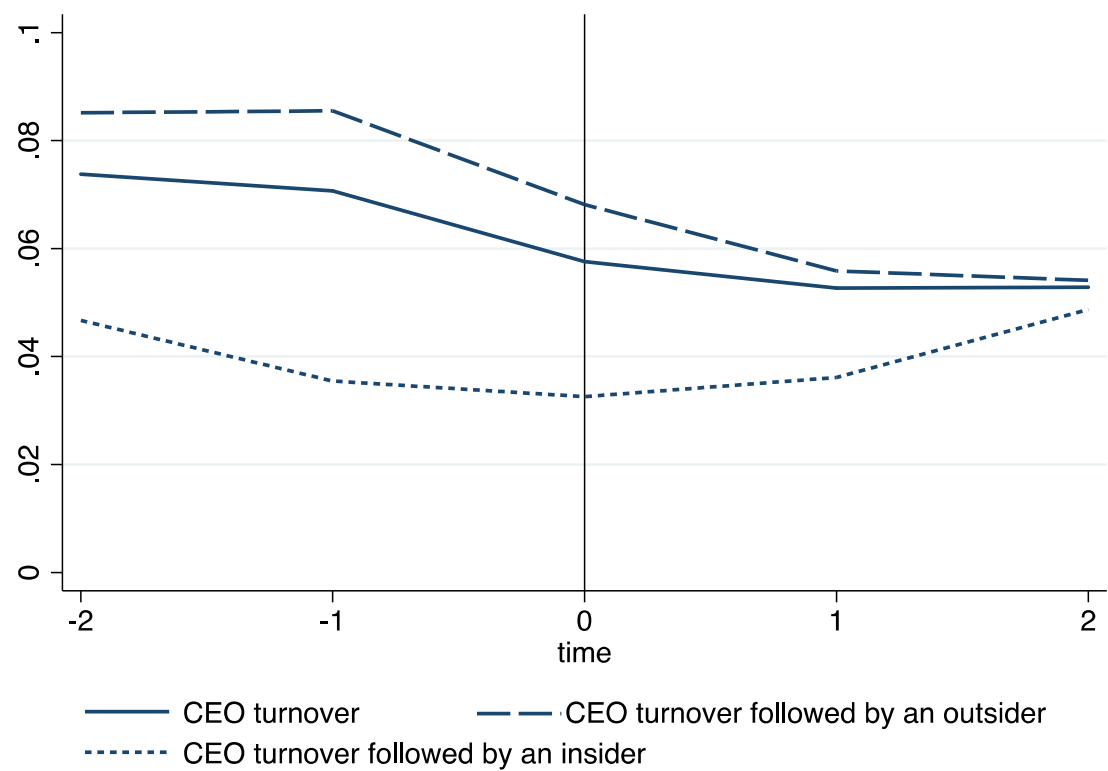


Table 1. Inputs and outputs: Mean values (1998-2012)

\begin{tabular}{cccccccccc}
\hline Year & $\begin{array}{c}\text { Deposits } \\
\left(\boldsymbol{x}_{\mathbf{1}}\right)\end{array}$ & $\begin{array}{c}\text { Fixed } \\
\text { assets } \\
\left(\boldsymbol{x}_{\mathbf{2}}\right)\end{array}$ & $\begin{array}{c}\text { Wages } \\
\left(\boldsymbol{x}_{\mathbf{3}}\right)\end{array}$ & $\begin{array}{c}\text { Admin. } \\
\text { expenses } \\
\left(\boldsymbol{x}_{\mathbf{4}}\right)\end{array}$ & $\begin{array}{c}\text { Total } \\
\text { loans } \\
(\boldsymbol{u}+\boldsymbol{b})\end{array}$ & $\begin{array}{c}\text { Performing } \\
\mathbf{c o a n s} \\
(\boldsymbol{u})\end{array}$ & $\begin{array}{c}\text { NPL } \\
(\boldsymbol{b})\end{array}$ & $\begin{array}{c}\text { Securities } \\
\left(\boldsymbol{v}_{\mathbf{1}}\right)\end{array}$ & $\begin{array}{c}\text { Service } \\
\mathbf{f e e s} \\
\left(\boldsymbol{v}_{\mathbf{2}}\right)\end{array}$ \\
\hline 1998 & 55,482 & 5,852 & 3,243 & 1,688 & 43,744 & 42,486 & 1,257 & 30,524 & 1,564 \\
1999 & 58,744 & 6,332 & 3,539 & 2,117 & 48,296 & 47,063 & 1,233 & 34,304 & 1,714 \\
2000 & 66,143 & 4,953 & 3,723 & 2,469 & 59,852 & 57,785 & 2,066 & 36,812 & 2,064 \\
2001 & 66,421 & 5,079 & 4,202 & 2,832 & 70,770 & 69,153 & 1,617 & 36,514 & 2,271 \\
2002 & 70,302 & 5,800 & 4,577 & 3,025 & 78,925 & 76,429 & 2,496 & 41,218 & 2,430 \\
2003 & 75,010 & 5,171 & 4,879 & 3,258 & 88,207 & 86,746 & 1,460 & 43,692 & 3,027 \\
2004 & 103,658 & 5,825 & 6,115 & 3,600 & 102,479 & 100,492 & 1,987 & 66,097 & 3,695 \\
2005 & 111,999 & 6,085 & 6,504 & 3,890 & 117,455 & 115,881 & 1,574 & 66,514 & 4,138 \\
2006 & 123,721 & 6,286 & 6,856 & 4,088 & 136,017 & 134,215 & 1,802 & 67,259 & 4,582 \\
2007 & 132,728 & 6,948 & 7,398 & 4,467 & 175,707 & 173,696 & 2,012 & 53,834 & 5,340 \\
2008 & 145,285 & 7,567 & 7,267 & 4,704 & 206,131 & 203,023 & 3,107 & 42,275 & 5,817 \\
2009 & 173,836 & 7,899 & 7,702 & 5,008 & 205,414 & 201,146 & 4,268 & 55,524 & 6,265 \\
2010 & 167,520 & 7,677 & 7,784 & 5,039 & 200,013 & 196,267 & 3,746 & 60,330 & 6,338 \\
2011 & 170,480 & 7,794 & 8,243 & 5,116 & 220,151 & 216,206 & 3,945 & 51,573 & 6,792 \\
2012 & 190,140 & 8,012 & 8,953 & 5,264 & 246,044 & 241,868 & 4,177 & 62,852 & 7,477 \\
Total & 110,951 & 6,431 & 5,925 & 3,686 & 128,746 & 126,341 & 2,405 & 49,031 & 4,097 \\
\hline
\end{tabular}

The sample includes information for the Costa Rican banking firms between 1998 and 2012. All monetary values are expressed in millions of 2012 Costa Rican colones, and are deflated with respect to inflation.

Table 2. Accounting performance and risk variables: Descriptive statistics

\begin{tabular}{lrrrr}
\hline \multicolumn{1}{c}{ Variable } & \multicolumn{1}{c}{ Mean } & \multicolumn{1}{c}{ S.D. } & \multicolumn{1}{c}{ Minimum } & \multicolumn{1}{c}{ Maximum } \\
\hline Total assets & 222,463 & 559,411 & 410 & $4,065,165$ \\
ROA & 0.0184 & 0.0434 & -0.7339 & 0.1088 \\
NIM & 0.0663 & 0.0345 & -0.0373 & 0.1943 \\
NPL ratio & 0.0210 & 0.0410 & 0.0000 & 0.6580 \\
CAR & 0.2284 & 0.1608 & 0.0441 & 0.9774 \\
\hline
\end{tabular}

The sample includes information for the Costa Rican banking firms between 1998 and 2012. Total assets are expressed in millions of 2012 Costa Rican colones. Return on assets (ROA) is defined as the ratio of net profit divided by total assets. The net interest margin (NIM) is the difference between interest income and interest expense relative to total assets. The capital adequacy ratio (CAR) divides equity and risk-weighted reserves by total assets. For the non-performing loans (NPL) ratio, NPL are divided by total loans. Number of observations: 663.

Table 3. Frequency table for CEO turnover during 2000-2010

\begin{tabular}{lcccccccccccc}
\hline & $\mathbf{2 0 0 0}$ & $\mathbf{2 0 0 1}$ & $\mathbf{2 0 0 2}$ & $\mathbf{2 0 0 3}$ & $\mathbf{2 0 0 4}$ & $\mathbf{2 0 0 5}$ & $\mathbf{2 0 0 6}$ & $\mathbf{2 0 0 7}$ & $\mathbf{2 0 0 8}$ & $\mathbf{2 0 0 9}$ & $\mathbf{2 0 1 0}$ & Total \\
\hline $\boldsymbol{\Delta}$ CEO & 5 & 3 & 2 & 7 & 3 & 5 & 6 & 2 & 5 & 4 & 7 & 49 \\
Insider & 2 & 0 & 0 & 4 & 0 & 1 & 2 & 1 & 1 & 2 & 2 & 15 \\
Outsider & 3 & 3 & 2 & 3 & 3 & 4 & 4 & 1 & 4 & 2 & 5 & 34 \\
\hline
\end{tabular}


Table 4. Efficiency scores: Descriptive statistics

\begin{tabular}{cccccc}
\hline Year & Obs. & Mean & S.D. & Min. & Max. \\
\hline 1998 & 51 & 0.1188 & 0.1565 & 0.0000 & 0.5143 \\
1999 & 50 & 0.1408 & 0.1738 & 0.0000 & 0.6307 \\
2000 & 50 & 0.1127 & 0.1517 & 0.0000 & 0.4671 \\
2001 & 47 & 0.0839 & 0.1220 & 0.0000 & 0.4316 \\
2002 & 47 & 0.0708 & 0.1079 & 0.0000 & 0.3857 \\
2003 & 46 & 0.0619 & 0.0940 & 0.0000 & 0.3257 \\
2004 & 42 & 0.0650 & 0.0963 & 0.0000 & 0.3248 \\
2005 & 40 & 0.0582 & 0.0843 & 0.0000 & 0.3430 \\
2006 & 41 & 0.0335 & 0.0530 & 0.0000 & 0.2255 \\
2007 & 40 & 0.0384 & 0.0656 & 0.0000 & 0.2322 \\
2008 & 42 & 0.0558 & 0.0857 & 0.0000 & 0.3057 \\
2009 & 42 & 0.0552 & 0.0973 & 0.0000 & 0.3448 \\
2010 & 42 & 0.0569 & 0.0909 & 0.0000 & 0.3318 \\
2011 & 42 & 0.0541 & 0.0806 & 0.0000 & 0.3530 \\
2012 & 41 & 0.0513 & 0.0755 & 0.0000 & 0.2484 \\
Total & 663 & 0.0728 & 0.1135 & 0.0000 & 0.6307 \\
\hline
\end{tabular}

Note that the number of observations stands for the number of reported scores, whereas the sequential technology also includes banks from the two previous years. Efficiency is computed according to equation (4).

Table 5. Accounting performance measures: Descriptive statistics

\begin{tabular}{cccccccccc}
\hline Year & Obs. & $\begin{array}{c}\text { ROA } \\
\text { Mean }\end{array}$ & S.D. & Min. & Max. & $\begin{array}{c}\text { NIM } \\
\text { Mean }\end{array}$ & S.D. & Min. & Max. \\
\hline 1998 & 51 & 0.0184 & 0.0327 & -0.1537 & 0.0777 & 0.0713 & 0.0461 & 0.0078 & 0.1738 \\
1999 & 50 & 0.0065 & 0.1094 & -0.7339 & 0.0930 & 0.0746 & 0.0506 & -0.0373 & 0.1943 \\
2000 & 50 & 0.0110 & 0.0685 & -0.4279 & 0.1009 & 0.0718 & 0.0443 & 0.0046 & 0.1906 \\
2001 & 47 & 0.0237 & 0.0237 & -0.0276 & 0.1015 & 0.0720 & 0.0383 & 0.0268 & 0.1694 \\
2002 & 47 & 0.0249 & 0.0257 & -0.0296 & 0.1086 & 0.0747 & 0.0364 & 0.0212 & 0.1742 \\
2003 & 46 & 0.0222 & 0.0209 & -0.0166 & 0.1075 & 0.0718 & 0.0317 & 0.0306 & 0.1631 \\
2004 & 42 & 0.0152 & 0.0675 & -0.3927 & 0.1066 & 0.0673 & 0.0296 & 0.0246 & 0.1602 \\
2005 & 40 & 0.0252 & 0.0181 & 0.0095 & 0.1088 & 0.0661 & 0.0320 & 0.0218 & 0.1769 \\
2006 & 41 & 0.0222 & 0.0160 & 0.0071 & 0.0941 & 0.0653 & 0.0289 & 0.0226 & 0.1455 \\
2007 & 40 & 0.0213 & 0.0174 & -0.0056 & 0.0827 & 0.0637 & 0.0272 & 0.0158 & 0.1395 \\
2008 & 42 & 0.0230 & 0.0162 & 0.0059 & 0.0771 & 0.0594 & 0.0240 & 0.0182 & 0.1212 \\
2009 & 42 & 0.0167 & 0.0161 & -0.0273 & 0.0751 & 0.0571 & 0.0226 & 0.0212 & 0.1112 \\
2010 & 42 & 0.0167 & 0.0168 & 0.0003 & 0.0812 & 0.0582 & 0.0237 & 0.0175 & 0.1215 \\
2011 & 42 & 0.0163 & 0.0175 & -0.0035 & 0.0969 & 0.0572 & 0.0258 & 0.0234 & 0.1327 \\
2012 & 41 & 0.0151 & 0.0191 & -0.0528 & 0.0942 & 0.0577 & 0.0251 & 0.0225 & 0.1309 \\
Total & 663 & 0.0184 & 0.0434 & -0.7339 & 0.1088 & 0.0663 & 0.0345 & -0.0373 & 0.1943 \\
\hline
\end{tabular}

Return on assets (ROA) is defined as the ratio of net profit divided by total assets. The net interest margin (NIM) is the difference between interest income and interest expense relative to total assets. 
Table 6. Performance changes around CEO turnover (2000-2010)

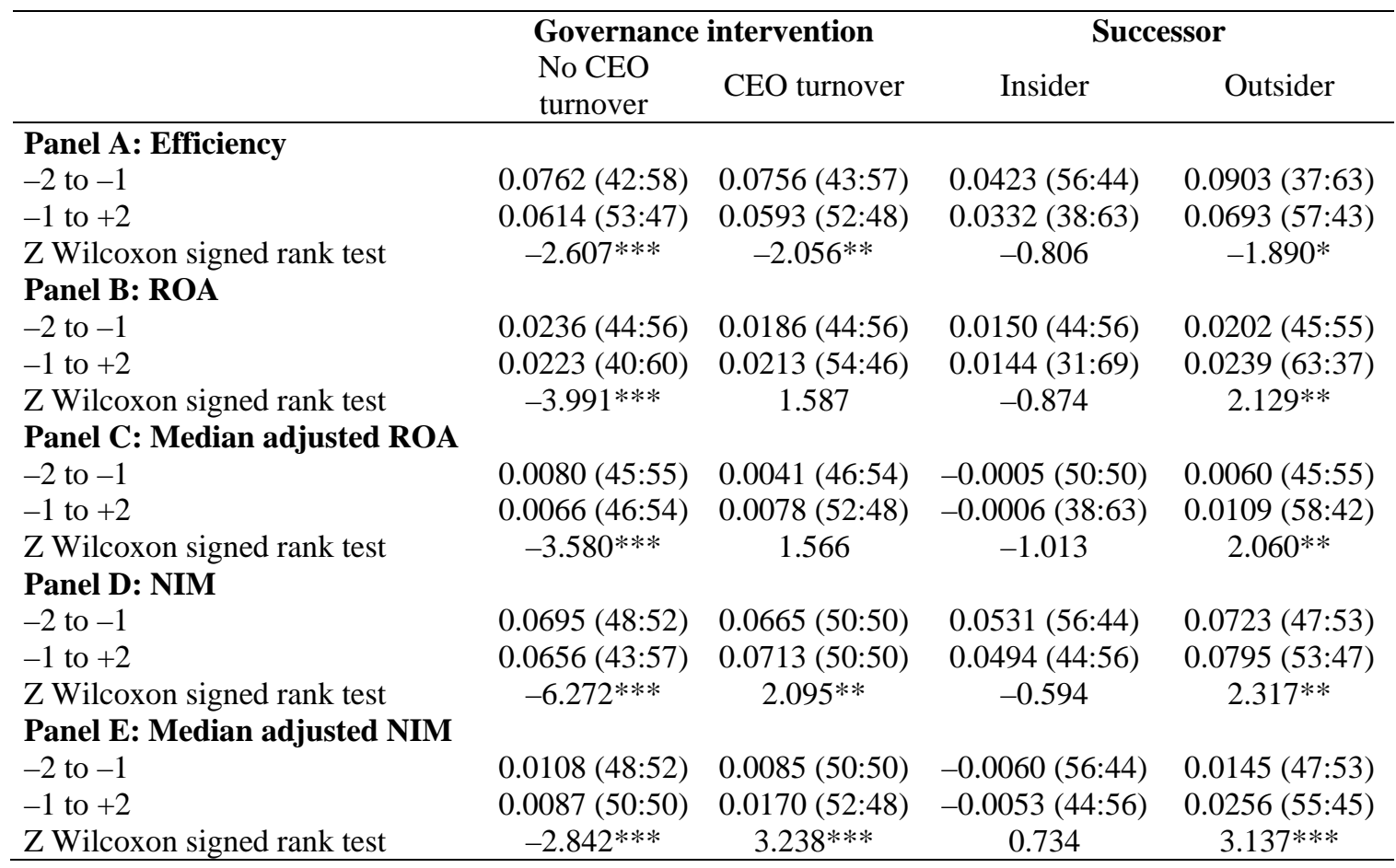

Percentage of firms with positive and negative changes in performance are reported in brackets (i.e. figures should be read as "percentage of positive changes : percentage of negative changes"). *, **, *** indicate significance at the $0.10,0.05$, and 0.01 level, respectively. 


\section{Appendix: Additional analyses of the effect of risk on firm performance}

A supplementary analysis examines the effect of risk on bank performance. This effect on efficiency and accounting ratios is obtained by estimating the following regression for the full period:

Performance $_{t}^{k}=\alpha_{0}+\beta_{1} \mathrm{NPL}_{t-1}^{k}+\beta_{2} \mathrm{CAR}_{t-1}^{k}+\beta_{3}$ Controls $_{t-1}^{k}+\psi_{t}+v_{t}^{k}$,

where: $k=1, \ldots, K$ and $t=1, \ldots, T$ represent the cross-sectional units and the time periods, respectively; $\psi_{t}$ is the time-specific effect and $v_{t}^{k}$ is the error term. The disturbance takes the form $v_{t}^{k} \sim N\left[0, \sigma_{v}^{k}\right]$ when the dependent variable is the efficiency score. When ROA and NIM are the dependent variables, the error term takes the form $v_{t}^{k}=\varepsilon^{k}+\eta_{t}^{k}$, where $\varepsilon^{k}$ is the unobserved timeinvariant firm-specific effect that controls for unobservable heterogeneity, and $\eta_{t}^{k}$ is a stochastic error term that varies cross-time and cross-units. Control variables are bank size, defined as the natural logarithm of total assets (lagged) and time dummies.

Our performance assessments imply using three different dependent variables: efficiency, ROA, and NIM. Due to their statistical properties, we use different techniques. When the efficiency score is the dependent variable ( $\delta^{k} \in[0,+\infty)$ ), we use a truncated regression (Greene 2003; Simar and Wilson 2011). Thus, the model takes the form $\delta^{k} \approx \alpha+\beta X^{\prime k}+v^{k}$. Parameter estimates are obtained by the maximum likelihood method, and disturbances are constructed through parametric bootstrapping (2,000 replications) to derive more accurate error terms.

Accounting ratios are unbounded by definition, so we can employ econometric tool that allows taking into consideration the unobserved and constant heterogeneity among the analysed banks. Also, the presence of firm specific unobservable fixed effects that can be correlated with some explanatory variables should be accounted for. Consequently, coefficients are estimated using the system generalised method of moments (GMM). For robustness, we also estimate fixed effects regressions and the results do not change. 
Table A1. Regression results

\begin{tabular}{lclc}
\hline & Truncated & \multicolumn{2}{c}{ GMM } \\
\hline & Efficiency & ROA & NIM \\
\hline NPL ratio $(t-1)$ & $1.6813^{* *}$ & $-0.1268^{* * *}$ & $-0.0466^{* *}$ \\
& $(0.6660)$ & $(0.0392)$ & $(0.0180)$ \\
CAR $(t-1)$ & -0.0155 & $0.0904^{* * *}$ & $0.1652^{* * *}$ \\
& $(0.0855)$ & $(0.0080)$ & $(0.0037)$ \\
Size (ln assets) $(t-1)$ & 0.0030 & 0.0001 & $-0.0006^{*}$ \\
Time dummies & $(0.0093)$ & $(0.0001)$ & $(0.0003)$ \\
Intercept & Yes & Yes & Yes \\
Pseudo R2 & -0.1001 & 0.0028 & $0.0344^{* * *}$ \\
Log likelihood & $(0.1886)$ & $(0.0147)$ & $(0.0067)$ \\
Wald test (chi2) & 0.0668 & & \\
Sargan test & 300.8492 & & $433.56 * * *$ \\
Test for AR1 & $56.72 * * *$ & $204.42^{* * *}$ & 40.28 \\
Test for AR2 & & 44.83 & $-1.99 * *$ \\
Average VIF & & 0.71 & 0.94 \\
& & -0.89 & 1.87 \\
Observations & 1.87 & 1.87 & 648 \\
& 648 & & \\
\hline
\end{tabular}

For the truncated regression using the efficiency score as dependent variable bootstrapped standard errors (2,000 iterations) are presented in brackets. For GMM regressions (ROA and NIM) robust standard errors are presented in brackets. *, **, *** indicate significance at the $0.10,0.05$, and 0.01 level, respectively. Results do not change significantly when introducing an interaction term between size and ownership type. 